\title{
BMJ Open Prelacteal feeding practice and its determinant factors among mothers having children less than 6 months of age in Bure district, Northwest Ethiopia: a community-based cross- sectional study
}

Ayenew Mose (D) , ${ }^{1}$ Haimanot Abebe (D) ${ }^{2}$

To cite: Mose A, Abebe $\mathrm{H}$. Prelacteal feeding practice and its determinant factors among mothers having children less than 6 months of age in Bure district, Northwest Ethiopia: a community-based crosssectional study. BMJ Open 2021;11:e046919. doi:10.1136/ bmjopen-2020-046919

- Prepublication history for this paper are available online. To view these files, please visit the journal online (http://dx.doi. org/10.1136/bmjopen-2020046919).

Received 13 January 2021 Accepted 18 August 2021
Check for updates

(c) Author(s) (or their employer(s)) 2021. Re-use permitted under CC BY-NC. No commercial re-use. See rights and permissions. Published by BMJ.

${ }^{1}$ Midwifery, Wolkite University, Welkite, Ethiopia

${ }^{2}$ Public Helath, Wolkite University, Welkite, Ethiopia

Correspondence to

Ayenew Mose;

ayenew8484@gmail.com

\section{ABSTRACT}

Objective The main aim of this study was to assess prelacteal feeding practice and its determinant factors among mothers having children less than 6 months of age in Bure district, Northwest Ethiopia.

Design Community-based cross-sectional study design. Setting Northern Ethiopia.

Participants The present study was conducted among 621 mothers who had children less than 6 months of age in Bure district, Northwest Ethiopia, from 1 March 2019 to 30 March 2019

Primary outcome Mothers prelacteal feeding practice, modelled using multivariable logistic regression.

Secondary outcome Determinant factors of prelacteal feeding practice.

Results This study found that the prevalence of prelacteal feeding practice was $11.6 \%$ ((95\% Cl $9.0 \%$ to $14.2 \%))$. Delayed initiation of breast feeding (adjusted OR, $\mathrm{AOR}=5.4$, $95 \% \mathrm{Cl} 2.2$ to 13.5), mothers who did not get counselling of breast feeding ( $\mathrm{AOR}=2.9,95 \% \mathrm{Cl} 1.2$ to 7.2 ), home delivery ( $\mathrm{AOR}=6.9,95 \% \mathrm{Cl} 2.2$ to 21.5), primiparous mothers ( $A O R=4.1,95 \% \mathrm{Cl} 1.4$ to 12.2), a newborn with history of neonatal illness (AOR=3.3, 95\% $\mathrm{Cl} 1.3$ to 8.5) and lack of postnatal care visits (AOR=3.9, 95\% Cl 1.3 to 11.8 ) were determinant factors of prelacteal feeding practice.

Conclusions Delayed initiation of breast feeding, mothers who did not get counselling of breast feeding, home delivery, primiparous mothers, newborns with a history of neonatal illness and lack of postnatal care visits were determinant factors of prelacteal feeding practice. Therefore, healthcare workers should provide a home to home health education for mothers on the merits of early initiation of breast feeding, promote institutional delivery, enhance maternal health-seeking behaviour and encourage mothers to have postnatal care visits is recommended.

\section{INTRODUCTION}

Prelacteal feeding (PLF) is the early introduction of foods and liquids other than breast
Strengths and limitations of this study

- This study was conducted in a community with a large catchment population that addresses both mothers who had a history of visiting health institutions and those mothers who did not have a history of visiting health institutions.

- It fills the gaps through identification of the predominant factors for prelacteal feeding practice.

- Recall bias due to study participants unable to remember what happened in the past 6 months. However, we were minimising it by giving adequate training for data collectors to give sufficient time during the interview for mothers and that helps mothers to remember what was happened in the previous 6 months.

- This study shares social desirability bias due to the data collection procedure, which was intervieweradministered questionnaires that might make mothers unable to express whether she was practice prelacteal feeding or not. To reduce these bias, data collectors were recruited from other non-selected districts.

milk before the first 3 days of neonatal life after delivery. ${ }^{1}$ Optimal breastfeeding practice is the cornerstone of child survival, nutrition, growth and development, and maternal health. ${ }^{2}$ Thus, WHO and UNICEF jointly recommend early initiation of breast feeding within 1 hour, exclusive breast feeding for the first 6 months, and continued breast feeding until the second birthday. ${ }^{3}$ Despite this recommendation only $39 \%$ of children younger than 6 months worldwide are exclusively breastfeed. ${ }^{4}$ PLF is commonly practised globally, particularly higher in low-income and middle-income countries. ${ }^{56}$

PLF practices can directly affect the growth and development of children and maternal 
health. ${ }^{7}$ It is estimated that PLF with other suboptimal breastfeeding practices contributes to 1.4 million children deaths every year, indicates $45 \%$ of neonatal mortality, $30 \%$ of diarrhoeal mortality and $18 \%$ of acute respiratory deaths of under 5 years of age children in low-income and middle-incomecountries. ${ }^{89}$ On the contemporary, scaling up of optimal breastfeeding practice including avoidance of PLF practice would save approximately 823000 children's death and 20000 mothers death from breast cancer every year. ${ }^{10}$

Furthermore, PLF practice exposes newborns to infections through deprivation of the best start of neonatal life by decreasing the newborns intake of colostrum which is rich in antibody, decreases bonding, increases the chance of early termination of exclusive breast feeding and reduces the amount of breast milk production. For mothers, PLF reduces the level of prolactin and oxytocin hormone, which in turn increase the risk of primary postpartum haemorrhage, delayed uterine involution and increase the risk of maternal morbidity and mortality. ${ }^{1811}$

Global and National Child Feeding Guidelines were discouraged the administration of prelacteal foods to the newborn. ${ }^{312}$ However, it is still a deep-rooted predominant nutritional malpractice in low-income and middleincome countries including Ethiopia. ${ }^{3}$ For instance, about $22.9 \%-40 \%$ of mothers practised PLF in Nepal, ${ }^{13}$ India ${ }^{14}$ and Latin America. ${ }^{15}$ A study conducted in 22 subSaharan Africa countries and Ethiopia shows that about $32.2 \%$ and $28.92 \%$ of mothers practised PLF, respectively. ${ }^{16}$ According to the previous study findings, the most commonly prelacteal foods given to the newborn were butter and plain water. Giving birth at home, giving birth through caesarean section, lack of postnatal visit and late initiation of breast feeding were reported as some of the determinant factors of PLF practice. ${ }^{5} 1819$

In conclusion, previous studies had methodological limitations, inconsistency of findings, conducted using a small sample size, and specifically, the determinant factors were not well studied in the study area. Therefore, the main aim of this study was to assess the prevalence of PLF practices and its determinant factors among mothers having children less than 6 months of age in Bure district, Northwest Ethiopia.

\section{METHODS}

\section{Study setting, design and period}

A community-based cross-sectional study design was conducted in Bure district, Northwest Ethiopia from 1 March 2019 to 30 March 2019. This study was part of our previous study, which was published elsewhere. Both studies were targeted to understand the factors that determining optimal breastfeeding practices in Ethiopia where neonatal mortality was unacceptably high. Additionally, we have used a similar methodology to access the study participants. ${ }^{20}$

Bure district is located in Amhara Regional State, West Gojjam Administrative Zone, Ethiopia. It is one of the 15 districts of West Gojjam Zone. It is found $148 \mathrm{~km}$ southwest of the Regional State capital, Bahir Dar, and $400 \mathrm{~km}$ northwest of Addis Ababa, the capital city of Ethiopia.

According to the Bure district health office, the total number of children less than 6 months was 2882, under 5 children, 17 956, women with childbearing age of, 31 221, and pregnancy/delivery was 3469 . There are 5 functional health centres, 4 medium private clinics and 20 health posts that provide primary healthcare services to the catchment population during the data collection period. In 2018, the district health office indicates that institutional delivery was $38 \%$, antenatal care (ANC) coverage was $90 \%$, postnatal care (PNC) coverage was $85 \%$ and immunisation coverage was $95 \%$.

\section{Source and study population}

All mothers who had children less than 6 months of age in Bure district were considered as source population and mothers who were found in the randomly selected kebeles were considered the study population.

\section{Inclusion criteria}

All mothers who had children less than 6 months of age, permanent residents and who lived in the study area for at least 6 months were included.

\section{Exclusion criteria}

Mothers who were critically ill and unable to respond during the data collection period were excluded.

\section{Study variables and measurements}

The outcome variable in this study was PLF practice. PLF is the administration of fluid or food other than breast milk to the newborns except drugs, vitamins, minerals and vaccines before breastfeeding initiation, usually on the first 3 days of neonatal life after delivery. ${ }^{3}$ In this study, PLF was measured dichotomously as 'yes' (practised PLF) and 'no' (did not practise PLF). For the explanatory variable, we have collected data on sociodemographic variables and obstetric healthcare service utilisation-related variables.

The conceptual framework was used to describe the determinant factors of PLF practice. Several literatures show sociodemographic characteristics affect PLF and obstetric healthcare service utilisation. On the other hand, infant-related factors affect PLF practice (figure 1). ${ }^{1621}$

In this study, maternal age was assessed by asking the age of mothers and categorised into: ' $\leq 21$ ', '22-29', '30-38' and '39+'. Maternal education status was categorised into: 'unable to read and write', 'can read and write without formal education', 'primary (grade 1-8)', 'secondary (grade 9-12)' and 'college/university and above'. Father occupation was assessed by categorising into 'unemployed' and 'employed'. Regarding obstetric health service utilisation-related variables, breastfeeding initiation; it was categorised into 'within 1 hour' and 'after 1 hour', ANC visit was categorised into 'yes' and 'no', the number of ANC visit was categorised into 'one time', 'two times', 'three times' and 'greater than or equal to four 


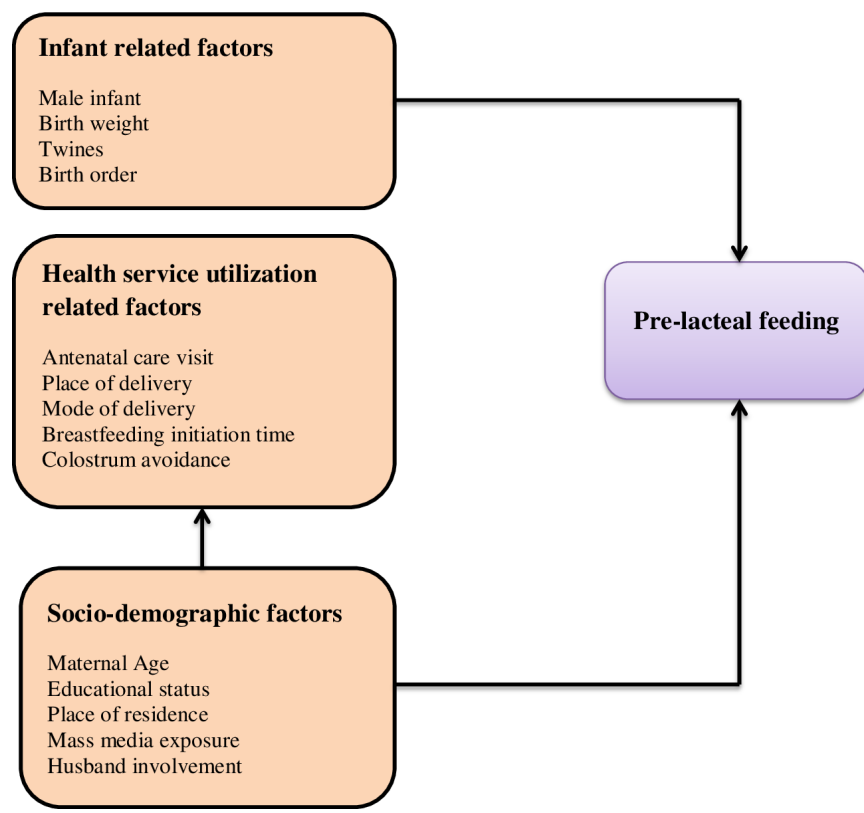

Figure 1 Conceptual frame work of predictors of prelacteal feeding practice.

times'. Concerning counselling on breast feeding during ANC visit, it was categorised into 'yes' and 'no'. Parity was categorised into 'primiparous' and 'multiparous', place of delivery was categorised into giving birth at 'health institution' and 'home'. ${ }^{21}$ Mode of delivery was categorised into giving birth via 'vaginal delivery' and 'caesarean section delivery', participated in an ANC care group was categorised into 'yes' and 'no'; PNC visit was categorised into 'yes' and 'no'; history of neonatal illness was categorised into 'yes' and 'no'. Delayed initiation of breast feeding is defined as the initiation of breast feeding after 1 hour of delivery. ${ }^{3}$ Early initiation of breast feeding is defined as the initiation of breast feeding within 1 hour following delivery. ${ }^{3}$

\section{Sample size determination and sampling procedure}

A single proportion formula was used to estimate the sample size by considering the following assumption $(p=14.2 \%)^{22}$ the proportion of the estimated level of PLF practice, and considering the assumption of $95 \%$ confidence level $\left(\mathrm{Z} \alpha /_{2}=1.96\right)$, $4 \%$ margin of error $(\mathrm{d}=0.04)$, and the design effect of $(\mathrm{d}=2)$, and adding the non-response rate of $10 \%$, the final sample size was 621 mothers. The data collectors go to the study participants for a consequent three times and those who were absent are considered as non-respondent.

A multistage stratified sampling technique was used to select the study participants at the community level. First, in the primary stage, Bure district has got 24 kebeles (the smallest administrative unit in Ethiopia having a total of 3000-5000 residents) (22 rural and 2 urban). In this study, the kebeles were considered clusters and they were stratified into urban and rural clusters. From 24 kebeles, 7 rural and 1 urban were selected using a simple random sampling technique. Second, in the secondary stage, the

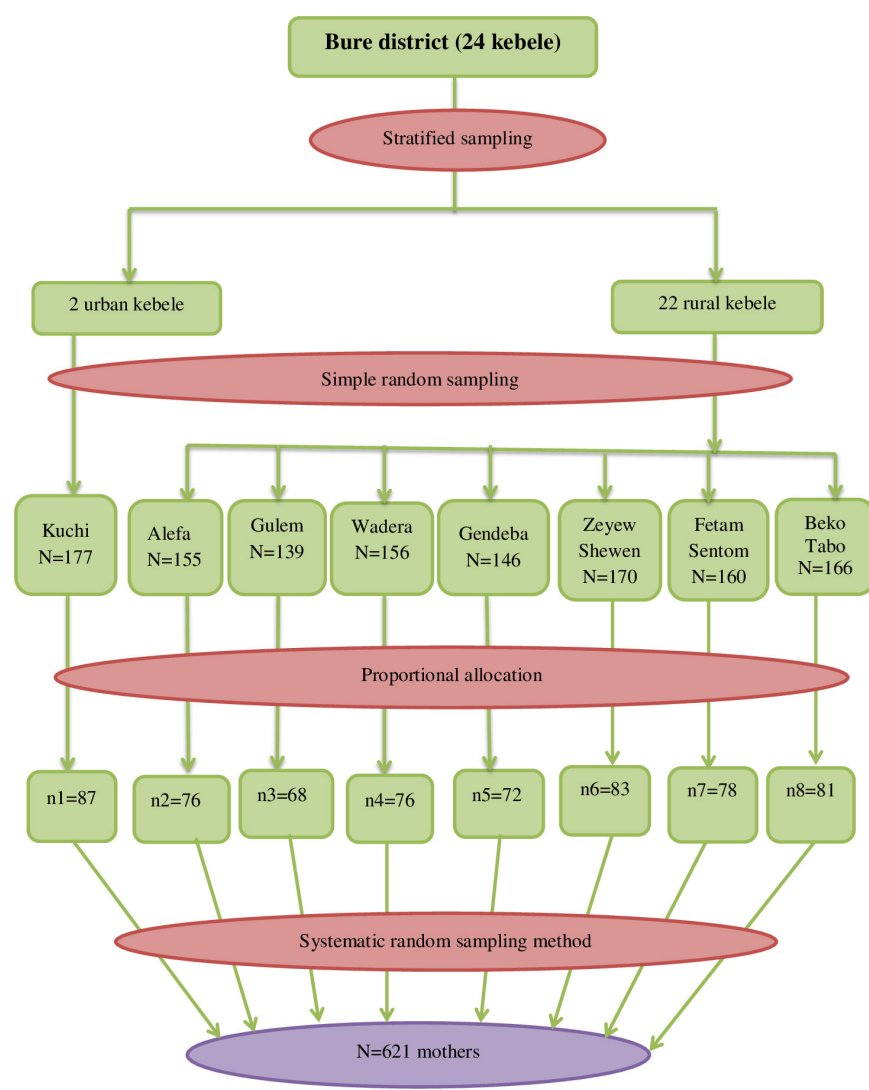

Figure 2 Schematic presentation of the sampling procedure.

census was conducted to identify those mothers having children less than 6 months of age in each eight kebele using the folder of community health extension workers registration book. A total of 1269 mothers having children less than 6 months of age were identified in the selected kebeles. Later on, the sample was allocated proportionally based on the number of mothers who had children less than 6 months in each selected kebele. The sampling interval was determined by dividing the total number of mothers who had children less than 6 months in each kebele into the final sample size $(1269 / 621)$ which gives a sampling interval of $(k=2)$. Finally, mothers who had children less than 6 months were selected using systematic random sampling until the total sample size was reached. The first case was selected using the lottery method at each kebele. In the case of twin newborns lottery method was used to select the study participants (figure 2).

\section{Data collection tool, procedure and quality control}

The questionnaires were adopted after reviewing different relevant literature. ${ }^{161819}$ Data were collected by face-to-face interviews using structured and close-ended questionnaires. To ensure quality, initially, the questionnaire was pretested 5\% (31) on non-selected kebele. A total of $12 \mathrm{BSc}$ midwife/nurses (8 diploma data collectors and 4 BSc supervisors) were recruited for data collection process. Two-day training was given to both data collectors and supervisors. 


\section{Data processing and analysis}

Data were entered into Epi Data V.4.2.0 and then exported to SPSS V.23 software package for further analysis. Descriptive analysis results were presented in the form of tables, figures and texts using frequencies and summary statistics including SD and percentage. In this study, the outcome variable was PLF practice among mothers having children less than 6 months of age. PLF practice was coded as ' 1 ', while not giving prelacteal foods was coded as ' 0 ' for regression analysis. Model fitness was checked using a Hosmer-Lemeshow goodness-of-fitness test (0.93). Bivariate logistic regression analysis was used to determine the association of each independent variable with the outcome variable by using binary logistic regression. The adjusted OR along with $95 \%$ CI was estimated to identify predictors for PLF practice by using multivariate analysis in binary logistic regression. In this study, a $\mathrm{p}<0.05$ was considered to declare a result as a statistically significant association.

\section{Patient and public involvement}

Neither patients nor public (all the people in the community) were involved in the development of this research.

\section{RESULTS}

\section{PLF practice}

Out of 621 study participants, $11.6 \%$ (95\% CI $9.0 \%$ to $14.2 \%$ ) of mothers reported that they gave prelacteal food to their newborns during the first 3 days after delivery. The most common type of prelacteal foods given was plain water, $23(3.7 \%)$, butter, $23(3.7 \%)$ and cow milk, $14(2.3 \%)$ (figure 3$)$. Above half of the mothers, $52.8 \%$ gave prelacteal food due to delays of breastfeeding initiation time (figure 4).

\section{Sociodemographic characteristics}

During the study period, there were a total of 2882 under 6-month children in Bure district, of which 1269 were found in the selected kebeles, and 645 mothers

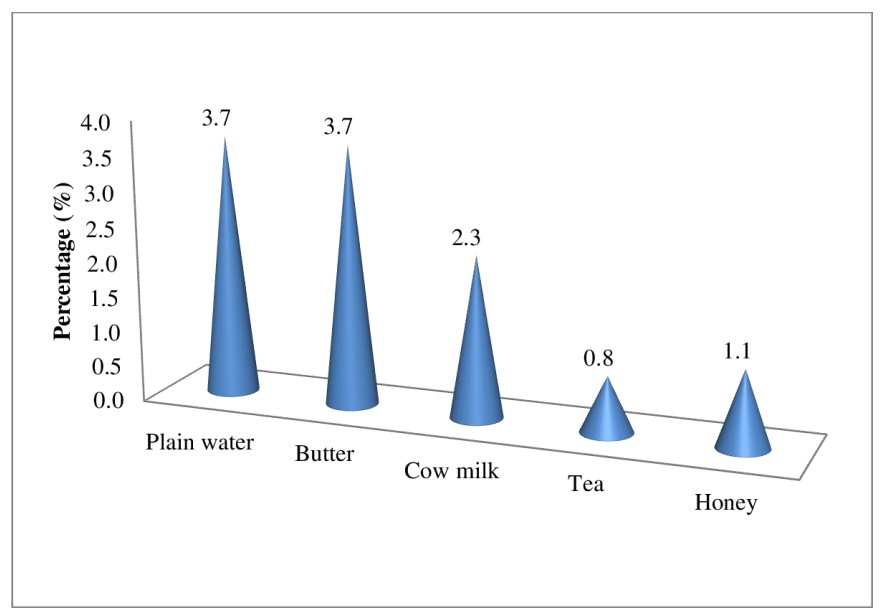

Figure 3 Types of prelacteal feeding received among mothers of children age less than 6 months in Bure district, Northwest Ethiopia, 2019 ( $n=72)$.

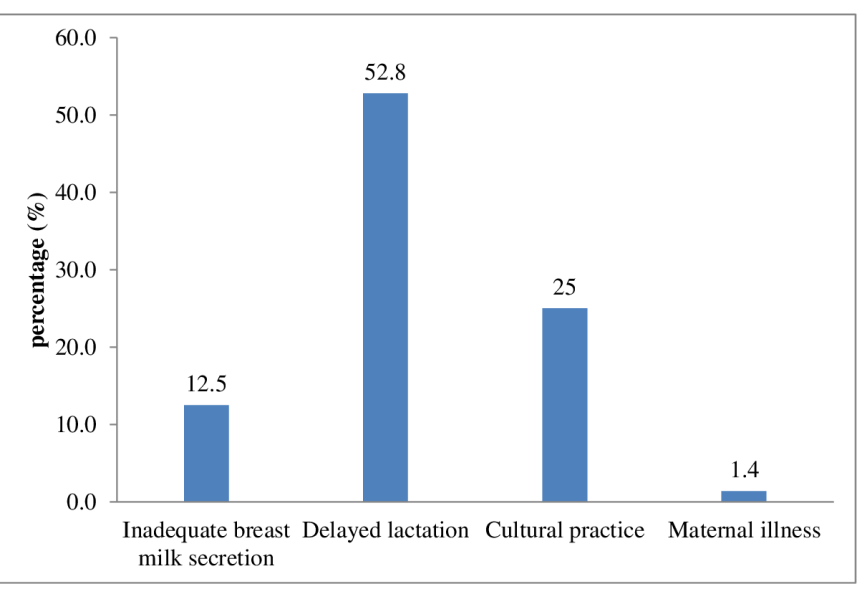

Figure 4 Reason of prelacteal feeding among mothers of children age less than 6 months in Bure district, Northwest Ethiopia, $2019(\mathrm{n}=72)$.

were eligible for this study (figure 5). After excluding non-respondent study participants $(n=24), 621$ study participants were involved in the final analysis, making a response rate of $97.3 \%$. The mean age of study participants was $29.96( \pm 6.149 \mathrm{SD})$ years. From the total respondents, $304(49 \%)$ were aged from 22 to 29 years old and the majority of the respondents, 549 (88.4\%) were married, $194(31.2 \%)$ were can read and write without formal education, and $586(94.4 \%)$ of the respondents were orthodox Christian religion followers. Out of the total respondents, $589(94.8 \%)$ were Amhara ethnicity. Regarding the infant's sex half, 314 (50.6\%) of the children were females (table 1).

\section{Obstetric healthcare service utilisation}

In this study, $340(54.8 \%)$ of mothers were multiparous. The majority, 459 (73.9\%) of mothers had ANC follow-up and $186(29.9 \%)$ of them were used four times, and 342 $(54 \%)$ of them have received breastfeeding counselling

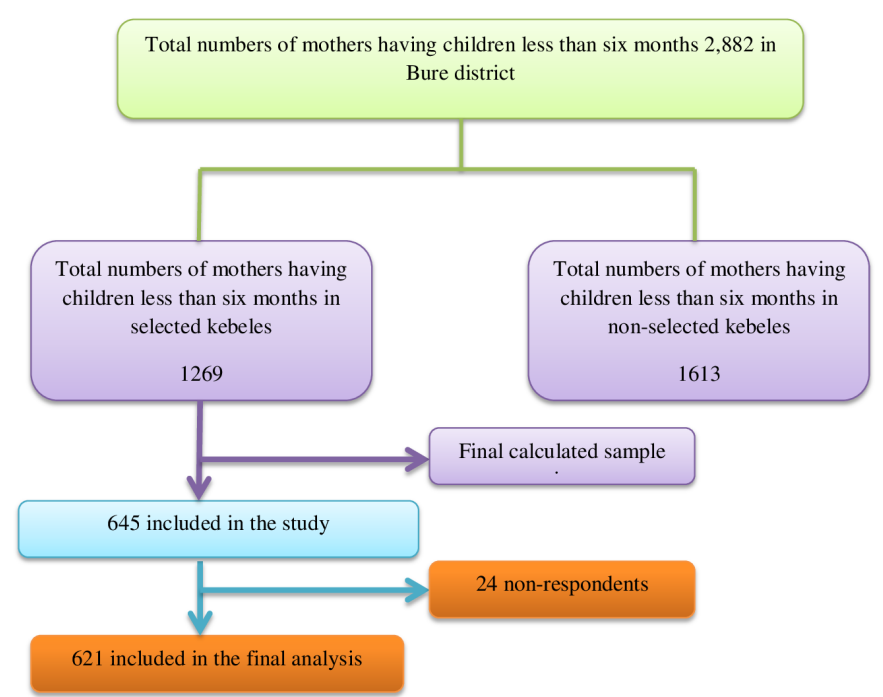

Figure 5 Flow chart of the study among mothers of children age less than 6 months in Bure district, Northwest Ethiopia, 2019. 
Table 1 Sociodemographic characteristics of mothers having children less than 6 months of age in Bure district, Northwest Ethiopia, $2019(n=621)$

\begin{tabular}{|c|c|c|}
\hline Variable & Frequency & $\%$ \\
\hline \multicolumn{3}{|l|}{ Maternal age } \\
\hline$\leq 21$ & 40 & 6.4 \\
\hline $22-29$ & 304 & 49.0 \\
\hline $30-38$ & 192 & 30.9 \\
\hline $39+$ & 85 & 13.7 \\
\hline \multicolumn{3}{|l|}{ Mother educational status } \\
\hline Unable to read and write & 140 & 22.5 \\
\hline $\begin{array}{l}\text { Can read and write without } \\
\text { formal education }\end{array}$ & 194 & 31.2 \\
\hline Grade 1-8 & 130 & 20.9 \\
\hline Grade 9-12 & 116 & 18.7 \\
\hline $\begin{array}{l}\text { College/university and } \\
\text { above }\end{array}$ & 41 & 6.6 \\
\hline \multicolumn{3}{|l|}{ Mother household head } \\
\hline Yes & 160 & 25.8 \\
\hline No & 461 & 74.2 \\
\hline \multicolumn{3}{|l|}{ Father occupation } \\
\hline Unemployed & 91 & 14.7 \\
\hline Employed & 530 & 85.3 \\
\hline \multicolumn{3}{|l|}{ Infant sex } \\
\hline Male & 307 & 49.4 \\
\hline Female & 314 & 50.6 \\
\hline \multicolumn{3}{|l|}{ Maternal religion } \\
\hline Orthodox & 586 & 94.4 \\
\hline Protestant & 28 & 4.5 \\
\hline Muslim & 7 & 1.1 \\
\hline \multicolumn{3}{|l|}{ Ethnicity } \\
\hline Amhara & 589 & 94.8 \\
\hline Oromo & 32 & 4.2 \\
\hline
\end{tabular}

at the ANC clinic. Five hundred and forty-three $(87.4 \%)$ of mothers gave birth through vaginal delivery. About 450 $(72.5 \%)$ of newborns did not have a history of neonatal illness. Regarding participation in women pregnant forums, $354(57 \%)$ mothers had not participated. About $555(89.4 \%)$ of mothers gave birth at health institutions, and $500(80.5 \%)$ of mothers had PNC visits. Concerning initiation of breast feeding, $515(82.9 \%)$ of mothers started early breastfeeding initiation within 1 hour (table 2).

\section{Factors associated with PLF practice}

Both bivariable and multivariable logistic regression analyses were carried out to identify variables associated with PLF practice. The result of bivariable logistic regression analysis showed that maternal age, maternal educational status, father occupation, breastfeeding initiation time, counselling on breast feeding, number of ANC visits,
Table 2 Obstetric healthcare service utilisation of mothers having children less than 6 months of age in Bure district, Northwest Ethiopia, 2019 ( $n=621)$

\begin{tabular}{|c|c|c|}
\hline Variable & Frequency & $\%$ \\
\hline \multicolumn{3}{|l|}{ Parity } \\
\hline Primiparous & 281 & 45.2 \\
\hline Multiparous & 340 & 54.8 \\
\hline \multicolumn{3}{|c|}{ Antenatal care (ANC) visit } \\
\hline Yes & 459 & 73.9 \\
\hline No & 162 & 26.1 \\
\hline \multicolumn{3}{|l|}{ No of ANC visit } \\
\hline 1 & 87 & 19 \\
\hline 2 & 103 & 22 \\
\hline 3 & 83 & 18 \\
\hline$\geq 4$ & 186 & 40.5 \\
\hline \multicolumn{3}{|c|}{ Breastfeeding counselling } \\
\hline Yes & 342 & 74.5 \\
\hline No & 117 & 25.5 \\
\hline \multicolumn{3}{|l|}{ Place of delivery } \\
\hline Health institution & 555 & 89.4 \\
\hline Home & 66 & 10.6 \\
\hline \multicolumn{3}{|l|}{ Mode of delivery } \\
\hline Vaginal & 543 & 87.4 \\
\hline Caesarean section & 78 & 12.6 \\
\hline \multicolumn{3}{|c|}{ Breastfeeding initiation time } \\
\hline Within 1 hour & 515 & 82.9 \\
\hline After 1 hour & 106 & 17.1 \\
\hline \multicolumn{3}{|l|}{ Neonatal illness } \\
\hline Yes & 171 & 27.5 \\
\hline No & 450 & 72.5 \\
\hline \multicolumn{3}{|c|}{ Participated in an ANC group } \\
\hline Yes & 267 & 43 \\
\hline No & 354 & 57 \\
\hline \multicolumn{3}{|l|}{ Postnatal care visit } \\
\hline Yes & 500 & 80.5 \\
\hline No & 121 & 19.5 \\
\hline
\end{tabular}

primiparous, home delivery, caesarean section delivery, participated in an ANC group, newborn with history of illness and lack of PNC visit were associated with PLF practice.

In multivariable logistic regression, all significant variables in binary logistic regression were adjusted at a $\mathrm{p} \leq 0.25$ to control the possible confounding factors. The result showed that delayed initiation of breast feeding, home delivery, mothers who did not get breastfeeding counselling, primiparous mothers, newborns with history of a neonatal illness and lack of PNC visits were determinant factors of PLF practice.

The odds of practising PLF among mothers who had late initiation of breast feeding were 5.4 times higher as compared with those mothers who initiate early breast 
feeding. The odds of practising PLF among mothers who did not receive breastfeeding counselling were 2.9 times as compared with those mothers who had received breastfeeding counselling. The odds of practising PLF among mothers who gave birth at home were 6.9 times as compared with those mothers who gave birth at health institutions. The odds of practising PLF among a newborn with a history of neonatal illness were 3.3 times higher as compared with their counterpart. The odds of practising PLF among primiparous mothers were four times higher as compared with those multiparous mothers. The odds of practising PLF among mothers who do not have PNC visits was 3.9 times higher as compared with those who had postnatal visits (table 3 ).

\section{DISCUSSION}

The present study revealed that about $11.6 \%$ of the infant had received prelacteal food within the first 3 days of neonatal life after birth. The prevalence of PLF in this study was lower than the studies conducted in Raya Kobo district $39 \%,{ }^{18}$ Enderta district $12.8 \%,{ }^{23}$ Mettu district $14.2 \%,{ }^{22}$ Bahir Dar 27\%, ${ }^{24}$ Motta town $20.3 \%,{ }^{25}$ Egypt $60 \%{ }^{21}$ and Vietnam $56.5 \% .{ }^{9}$ However, it was higher than a study conducted in the Southern part of Ethiopia, Arba Minch $8.9 \% .^{26}$ The possible explanation for the difference might be due to study population difference, access to health service, sample size determination, methodological and study areas difference; for instance, the sociocultural and ethnic background difference might affect optimal breastfeeding practice. In the case of study population difference, there might be a difference in the number of multiparous mothers across districts that might less likely to practice PLF due to their frequent exposure to healthcare workers.

The most common PLF practised in Bure district were; butter $(2.7 \%)$, water $(2.7 \%)$ and cow milk $(2.3 \%)$. The finding was congruent with the study conducted in Raya Kobo district and Mizan-Aman town, Benchi-Maji zone and Egypt. ${ }^{182127}$ The possible explanation might be due to mothers considered the introduction of plain water and butter will relieve infants hunger and thirst. Additionally, mothers thought the introduction of prelacteal food will facilitate the growth and development of infants.

Mothers who had delayed initiations of breast feeding (ie, after 1 hour of birth) were 5.4 times more likely to practice PLF compared with those mothers who initiated early breastfeeding practice (ie, within 1 hour of delivery). The possible justification might be during delayed initiation of breast feeding there might be the separation of mothers and newborns due to childbirth complications such as maternal sepsis, postpartum haemorrhage and the effect of anaesthesia after caesarean section that might give sufficient time to give prelacteal food for newborn to replace maternal breast milk. The result was consistent with the study conducted in Raya Kobo district. ${ }^{18}$ The possible explanation might be due to the similarity of the study population in breastfeeding practice and they are also found in the same ethnic background.

Mothers who did not receive breastfeeding counselling were 2.9 times more likely to practice PLF compared with those mothers who had received breastfeeding counselling. The possible explanation might be those mothers who did not receive breastfeeding counselling might lack awareness regarding the negative impact of the introduction of prelacteal foods to their newborns. The present study revealed that those mothers who gave birth at home were 6.9 times more likely to practice PLF compared with those mothers who had given birth at health institutions. The finding was consistent with the study conducted in Raya Kobo district and Mettu district. ${ }^{1822}$ The possible explanation might be those mothers who gave birth at home might lack information regarding the demerits of practising PLF. Moreover, those mothers who gave birth at home are exposed to traditional birth attendants, parents and relatives who might encourage the administration of prelacteal foods to the newborn.

Mothers who did not have postnatal visits were 4.1 times more likely to practise PLF compared with their counterparts. The possible reason could be that mothers who didn't come to postnatal visit, particularly during the first 3 days after delivery might lack counselling of optimal breastfeeding practice and as a result, they will have a tendency to give water, tea, and honey to their newborn.

The odds of practising PLF among mothers who had a newborn with a history of neonatal illness were 3.3 times higher than their counterparts. The possible explanation might be during neonatal illness, mothers could try a different alternative to treat neonatal illness at home. For instance, a mixed-method study conducted in Amhara shows for the treatment of sick newborns holy water/ Kurban/was received at churches as a mechanism to avoid ailments in neonates as well as parents. ${ }^{28}$

Our study showed that primiparous mothers were 4.1 times more likely to practise PLF as compared with the multiparous mothers. The finding was comparable with a study conducted in Egypt. ${ }^{21}$ The possible justification could be those primiparous mothers might lack awareness and experience regarding the optimal breastfeeding practice compared with their counterparts.

To summarise, the present study had several strengths. For instance, this study identifies multiple predominant determinant factors of PLF practice that help healthcare workers to emphasise the identified factors and further avoid PLF practice in the study area. Moreover, this study was conducted in a large community including both mothers who had a history of visiting health institutions and those who had not, which helps the researcher to generalise the finding of this study for other similar populations.

On the other hand, this study was not void of limitations. The present study might be affected by recall bias that mothers might encounter difficulties to recall the experience in the past 6 months such as type of prelacteal foods and some obstetric health service variable. To reduce this 
Table 3 Univariable and multivariable logistic regression of predictors of prelacteal feeding practice among mothers having children less than 6 months of age in Bure district, Northwest Ethiopia $(n=621)$

\begin{tabular}{|c|c|c|c|c|}
\hline \multirow[b]{2}{*}{ Variables } & \multicolumn{2}{|c|}{ Prelacteal feeding } & \multirow[b]{2}{*}{ COR $(95 \% \mathrm{Cl})$} & \multirow[b]{2}{*}{ AOR $(95 \% \mathrm{Cl})$} \\
\hline & No (\%) & Yes (\%) & & \\
\hline \multicolumn{5}{|l|}{ Maternal age } \\
\hline$<21$ & $32(80)$ & $8(20)$ & 1 & 1 \\
\hline $22-29$ & $278(91.4)$ & $26(8.6)$ & $0.37(0.16 \text { to } 0.89)^{*}$ & 0.44 (0.05 to 3.91$)$ \\
\hline 30-38 & $169(88)$ & $23(12)$ & 0.54 (0.22 to 1.32$)$ & $1.13(0.23$ to 5.59$)$ \\
\hline $39+$ & $70(82)$ & $15(18)$ & 0.67 (0.33 to 2.23 ) & 3.12 (0.67 to 14.47$)$ \\
\hline \multicolumn{5}{|l|}{ Maternal educational status } \\
\hline Unable to read and write & $112(80)$ & $28(20)$ & 1 & 1 \\
\hline $\begin{array}{l}\text { Can read and write without formal } \\
\text { education }\end{array}$ & $181(93)$ & $13(7)$ & $0.29(0.14 \text { to } 0.58)^{\star}$ & 2.57 (0.37 to 17.76$)$ \\
\hline Grade $1-8$ & $113(87)$ & $17(13)$ & $0.6(0.31$ to 1.16$)$ & 0.61 (0.09 to 4.15$)$ \\
\hline Grade 9-12 & $105(90.5)$ & $11(9.5)$ & $0.42(0.19 \text { to } 0.88)^{\star}$ & 2.19 (0.35 to 13.78$)$ \\
\hline College/university and above & $38(92.7)$ & $3(7.3)$ & 0.32 (0.09 to 1.09$)$ & 0.73 (0.09 to 5.74$)$ \\
\hline \multicolumn{5}{|l|}{ Father occupation } \\
\hline Unemployed & $74(83)$ & $17(17)$ & $1.98(1.09 \text { to } 3.6)^{\star}$ & 1.91 (0.51 to 7.09$)$ \\
\hline Employed & $475(89.6)$ & $55(10.4)$ & 1 & 1 \\
\hline \multicolumn{5}{|l|}{ Breastfeeding initiation } \\
\hline Within 1 hour & $484(94)$ & $31(6)$ & 1 & 1 \\
\hline After 1 hour & $65(61)$ & $41(39)$ & $9.85{\text { (5.78 to } 16.79)^{*}}^{*}$ & $5.41(2.17 \text { to } 13.49)^{\star *}$ \\
\hline \multicolumn{5}{|l|}{ Breastfeeding counselling } \\
\hline Yes & $326(95)$ & $16(5)$ & 1 & 1 \\
\hline No & $96(82)$ & $21(18)$ & $4.46(2.24 \text { to } 8.88)^{*}$ & $2.87(1.15 \text { to } 7.19)^{\star}$ \\
\hline \multicolumn{5}{|l|}{ No of antenatal care visit } \\
\hline 1 & $75(86)$ & $12(14)$ & 1 & 1 \\
\hline 2 & $94(90.4)$ & $10(9.6)$ & 0.67 (0.27 to 1.62$)$ & 0.96 (0.24 to 3.75$)$ \\
\hline 3 & $75(90.3)$ & $8(9.7)$ & 0.67 (0.26 to 1.72$)$ & 1.09 (0.29 to 4.13$)$ \\
\hline$\geq 4$ & $179(96.8)$ & $6(3.2)$ & $0.21(0.08 \text { to } 0.58)^{\star}$ & $1.67(0.451$ to 6.16$)$ \\
\hline \multicolumn{5}{|l|}{ Parity } \\
\hline Primiparous & $233(83)$ & $48(17)$ & $2.71(1.62 \text { to } 4.56)^{*}$ & $4.13(1.39 \text { to } 12.23)^{\star}$ \\
\hline Multiparous & $316(93)$ & $24(7)$ & 1 & 1 \\
\hline \multicolumn{5}{|l|}{ Place of delivery } \\
\hline Health institution & 507 (91.4) & $48(8.6)$ & 1 & 1 \\
\hline Home & $42(63.6)$ & $24(36.4)$ & $6.04(3.37 \text { to } 10.81)^{*}$ & $6.87(2.2 \text { to } 21.45)^{\star \star}$ \\
\hline \multicolumn{5}{|l|}{ Mode of delivery } \\
\hline Vaginal & $494(91)$ & $49(8)$ & 1 & 1 \\
\hline Caesarean section & $55(70.5)$ & $23(29.5)$ & $4.22(2.34 \text { to } 7.44)^{\star}$ & 2.5 (0.82 to 7.69$)$ \\
\hline \multicolumn{5}{|l|}{$\begin{array}{l}\text { Participated in an antenatal care } \\
\text { group }\end{array}$} \\
\hline Yes & $256(96)$ & $11(4)$ & 1 & 1 \\
\hline No & $293(82.8)$ & $61(17.2)$ & $4.85(2.49 \text { to } 9.41)^{\star}$ & 2.51 (0.97 to 6.49$)$ \\
\hline \multicolumn{5}{|l|}{ Neonatal illness } \\
\hline Yes & $136(79.5)$ & $35(20.5)$ & $2.87(1.74 \text { to } 4.47)^{*}$ & $3.31(1.29 \text { to } 8.45)^{*}$ \\
\hline No & $413(91.8)$ & $37(8.2)$ & 1 & 1 \\
\hline \multicolumn{5}{|l|}{ Postnatal care visit } \\
\hline Yes & $457(91.4)$ & $43(8.6)$ & 1 & 1 \\
\hline
\end{tabular}

Continued 
Table 3 Continued

\begin{tabular}{|c|c|c|c|c|}
\hline \multirow[b]{2}{*}{ Variables } & \multicolumn{2}{|c|}{ Prelacteal feeding } & \multirow[b]{2}{*}{ COR $(95 \% \mathrm{Cl})$} & \multirow[b]{2}{*}{ AOR $(95 \% \mathrm{Cl})$} \\
\hline & No (\%) & Yes (\%) & & \\
\hline No & $92(76)$ & $29(24)$ & $3.35(1.99 \text { to } 5.64)^{*}$ & $3.97(1.33 \text { to } 11.83)^{*}$ \\
\hline
\end{tabular}

${ }^{*} \mathrm{P}<0.05,{ }^{* *} \mathrm{p}<0.01$.

AOR, adjusted OR; COR, crude OR.

bias, the principal investigator had given 2-day training for data collectors and supervisors, particularly on giving adequate time for the mother till she had remembered her experience regarding PLF practice. Additionally, this study might be affected by social desirability bias, since mothers might not answer correctly regarding PLF practice due to the data collection approach which was an interview administered questionnaire. In fact, data collectors were recruited from other non-selected districts to decrease the introduction of social desirability bias.

\section{CONCLUSION}

The finding of this study shows that approximately 1 in 10 infants was received prelacteal foods following birth within the first 3 days after delivery. Delayed initiation of breast feeding, mothers who did not get counselling about breast feeding, home delivery, primiparous mothers, a newborn with a history of neonatal illness and lack of PNC visits are the important determinant factors of PLF practice in the study area. Therefore, healthcare workers should provide a home to home health education for mothers on the merits of early initiation of breast feeding, promote institutional delivery, enhance maternal health-seeking behaviour and encourage mothers to have $\mathrm{PNC}$ visits is recommended.

Acknowledgements The authors are grateful for the data collectors and study participants.

Contributors AM wrote the proposal, carried out the study and undertook statistical analysis. AM and HA have equally contributed in writing of the manuscript and approved the submitted version of the manuscript. All authors read and approved the final manuscript.

Funding All cost was covered by researchers.

Competing interests None declared.

Patient consent for publication Not required.

Ethics approval Before conducting this study, ethical clearance was obtained from Haramaya University College of Health and Medical Sciences Institutional Health Research Ethical Review Committee with a reference (CHMS/11/19). Later on, an official letter was written to Bure district health office. Next, a cooperation letter was written to all kebeles on which the study was carried out. The study, purpose, procedure and duration, possible risks and benefits were clearly explained for the study participants using local language (Amharic Language). The data collection was begun after written consent was taken from each study participant. The study participants were informed that they have the right to withdraw from the study at any time during data collection.

Provenance and peer review Not commissioned; externally peer reviewed.

Data availability statement Data are available on reasonable request.

Open access This is an open access article distributed in accordance with the Creative Commons Attribution Non Commercial (CC BY-NC 4.0) license, which permits others to distribute, remix, adapt, build upon this work non-commercially, and license their derivative works on different terms, provided the original work is properly cited, appropriate credit is given, any changes made indicated, and the use is non-commercial. See: http://creativecommons.org/licenses/by-nc/4.0/.

\section{ORCID iDs}

Ayenew Mose http://orcid.org/0000-0003-4353-7791

Haimanot Abebe http://orcid.org/0000-0001-5885-5982

\section{REFERENCES}

1 UNICEF. From the first making the case for from the first, 2016. Available: https://data.unicef.org/resources/first-hour-life-new-reportbreastfeeding-practices/

2 WHO. Protecting, promoting and supporting breastfeeding in facilities providing maternity and newborn services, 2017. Available: https://apps.who.int/iris/bitstream/handle/10665/259386/ 9789241550086-eng.pdf

3 WHO. Global strategy for infant and young child feeding, 2003.

4 Mosquera PS, Lourenço BH, Gimeno SGA, et al. Factors affecting exclusive breastfeeding in the first month of life among Amazonian children. PLoS One 2019;14:e0219801-16.

5 Temesgen H, Negesse A, Woyraw W, et al. Prelacteal feeding and associated factors in Ethiopia: systematic review and meta-analysis. Int Breastfeed J 2018;13:1-12.

6 Rahmartani LD, Carson C, Quigley MA. Prevalence of prelacteal feeding and associated risk factors in Indonesia: evidence from the 2017 Indonesia demographic health survey. PLoS One 2020;15:e0243097-19.

7 Ersino G, Henry CJ, Zello GA. Suboptimal feeding practices and high levels of undernutrition among infants and young children in the rural communities of Halaba and Zeway, Ethiopia. Food Nutr Bull 2016;37:409-24.

8 UNICEF. Scientific rationale: benefits of breastfeeding, 2012. Available: https://www.unicef.org/nutrition/files/Scientific_rationale_ for_benefits_of_breasfteeding.pdf

9 Nguyen P, Binns CW, Ha AVV, Van HAV, et al. Prelacteal and early formula feeding increase risk of infant hospitalisation: a prospective cohort study. Arch Dis Child 2020;105:122-6.

10 Victora CG, Bahl R, Barros AJD, et al. Breastfeeding in the 21st century: epidemiology, mechanisms, and lifelong effect. Lancet 2016;387:475-90.

11 Tessema M, Belachew T, Ersino G. Feeding patterns and stunting during early childhood in rural communities of Sidama South Ethiopia. Pan Afr Med J 2013;14:1-12.

$12 \mathrm{FMOH}$. National strategy for infant and young child feeding. Ethiopia, 2004.

13 Karkee R, Lee AH, Khanal V, et al. Initiation of breastfeeding and factors associated with Prelacteal feeds in central Nepal. J Hum Lact 2014;30:353-7.

14 Das A, Sai Mala G, Singh RS, et al. Prelacteal feeding practice and maintenance of exclusive breast feeding in Bihar, India - identifying key demographic sections for childhood nutrition interventions: a cross-sectional study. Gates Open Res 2019;3:1-13.

15 Boccolini CS, Pérez-Escamilla R, Giugliani ERJ, et al. Inequities in milk-based prelacteal feedings in Latin America and the Caribbean: the role of cesarean section delivery. J Hum Lact 2015;31:89-98.

16 Belachew AB, Kahsay AB, Abebe YG. Individual and communitylevel factors associated with introduction of prelacteal feeding in Ethiopia. Arch Public Health 2016;74:1-11.

17 Berde AS, Ozcebe H. Risk factors for prelacteal feeding in subSaharan Africa: a multilevel analysis of population data from twentytwo countries. Public Health Nutr 2017;20:1953-62.

18 Legesse M, Demena M, Mesfin F, et al. Prelacteal feeding practices and associated factors among mothers of children aged less than 
24 months in Raya Kobo district, North Eastern Ethiopia: a crosssectional study. Int Breastfeed J 2014;9:1-8.

19 Bililign N, Kumsa H, Mulugeta M, et al. Factors associated with prelacteal feeding in North eastern Ethiopia: a community based cross-sectional study. Int Breastfeed J 2016;11:1-7.

20 Mose A, Dheresa M, Mengistie B, et al. Colostrum avoidance practice and associated factors among mothers of children aged less than six months in Bure district, Amhara region, North West, Ethiopia: a community-based cross-sectional study. PLoS One 2021:16:e0245233-11.

21 Abd D, Salam E, Yacout A. Pre-lacteal feeding practices and its predominant factors among mothers ' of infants in Damanhour. IOSR-JNHS 2019;8:26-38.

22 Wolde TF, Ayele AD, Takele WW. Prelacteal feeding and associated factors among mothers having children less than 24 months of age, in Mettu district, Southwest Ethiopia: a community based crosssectional study. BMC Res Notes 2019;12:3-9.

23 Teka B, Assefa H, Haileslassie K. Prevalence and determinant factors of exclusive breastfeeding practices among mothers in
Enderta woreda, Tigray, North Ethiopia: a cross-sectional study. Int Breastfeed J 2015;10:2-7.

24 Seid AM, Yesuf ME, Koye DN. Prevalence of exclusive breastfeeding practices and associated factors among mothers in Bahir Dar City, Northwest Ethiopia: a community based cross-sectional study. Int Breastfeed J 2013;8:1-8.

25 Tewabe T. Prelacteal feeding practices among mothers in Motta town, Northwest Ethiopia: a cross-sectional study. Ethiop J Health Sci 2018;28:393-402.

26 Adugna DT. Women's perception and risk factors for delayed initiation of breastfeeding in Arba Minch Zuria, Southern Ethiopia. Int Breastfeed J 2014;9:1-8.

27 Amare M. Assessmentof prevalence of pre-lacteal feeding and associated factors in mizan-aman town benchmaji zone, South West Ethiopia, 2015, 2016.

28 Asfaha MD, Comeau DL, Spangler SA, et al. Neonatal care and community-level treatment seeking for possible severe bacterial infection (Psbl) in Amhara, Ethiopia. BMC Health Serv Res 2020;20:264 